\title{
Optimizing targeted gene flow to maximize local genetic diversity: when and how to act under various scenarios of environmental change.
}

\author{
Adam Smart ${ }^{1}$ and Ben Phillips ${ }^{1}$ \\ ${ }^{1}$ The University of Melbourne
}

November 30, 2020

\begin{abstract}
Targeted gene flow is an emerging conservation tool which involves introducing a cohort of individuals with particular traits to locations where they can produce a conservation benefit. This approach is being proposed to adapt recipient populations to a known threat, but questions remain surrounding how best to maximize conservation outcomes during periods of continuous directional environmental change. Here we introduce a new management objective - to keep the recipient population extant and with maximum diversity of local alleles - and we explore how varying the timing and size of an introduction can achieve this. Our results reveal that management levers can often optimize this so that nearly $100 \%$ of the allelic diversity is preserved. These optimum outcome sets are robust to the shape of the environmental change but are highly sensitive to the the maximum magnitude of change and the level of outbreeding depression in the system.
\end{abstract}

\section{Hosted file}

Smart_geneticTiming_ME_Revised_Sub.pdf available at https://authorea.com/users/379788/ articles/496009-optimizing-targeted-gene-flow-to-maximize-local-genetic-diversity-whenand-how-to-act-under-various-scenarios-of-environmental-change 